\title{
Electronic Declaration of Assets as a Way to Prevent Corruption
}

\author{
Aisulu A. Nurkey ${ }^{1 *}$, Aigul B. Kosherbayeva ${ }^{1}$, Nurzhan K. Kuandykov ${ }^{1}$ \\ ${ }^{I}$ Academy of Public Administration under the President of the Republic of Kazakhstan \\ 33 a Abay Ave., 010000, Nur-Sultan, Kazakhstan
}

\begin{abstract}
The asset declaration contains valuable information to help uncover misconduct and illicit enrichment and to ensure that managers are held accountable, and their assets are not acquired through corruption. In general, the use of the electronic type of income declaration has a positive effect on combating corruption. Nevertheless, having numerous positive features, this species also contains a number of disadvantages and difficulties. Many states and international organizations are introducing declarations of income and assets to reduce the level of the shadow economy. As a result, it was revealed that in the states where the practice of declaring income and assets was introduced in the early period, the level of corruption crimes has been reduced. However, there is still debate about the adoption of this mechanism as an anti-corruption tool. This article examines not only the work of researchers in the field of declaring and combating corruption but also international research, the experience of which can also be used in Kazakhstan. This article examines the effectiveness of using the declaration of income and assets, including universal declaration, through electronic media to combat corruption. For the analysis, a SWOT analysis was selected, through which the main key points were assessed and recommendations were developed, especially for the Kazakhstan anti-corruption policy. The result of this analysis showed that the implementation of universal declaration through electronic resources is certainly an effective activity, but costs and challenges, such as cybersecurity, streamlining of business management processes, technical errors, and system failures, must also be taken into account.
\end{abstract}

Keywords: corruption, universal declaration, digitalization, income declaration, anti-corruption

For citation: Nurkey, A.A., Kosherbayeva, A.B., \& Kuandykov N.K. 2021). Electronic Declaration of Assets as a Way to Prevent Corruption. Economics: the Strategy and Practice, 16(4), 208-217, https://doi.org/10.51176/19979967-2021-4 -208-217

* Corresponding author: Nurkey A.A. - PhD candidate, Academy of Public Administration under the President of the Republic of Kazakhstan, 33a Abai Ave., 010000, Nur-Sultan, Kazakhstan, 877172753497, e-mail: a.nurkey@ gmail.com,

Conflict of interests: the authors declare that there is no conflict of interest

Financial support: The study was not sponsored (own resources).

The article received: 07.10 .2021

The article approved for publication: 28.12 .2021

Date of publication: 30.12 .2021 


\title{
Сыбайлас жемқорлықтың алдын алу әдісі ретінде активтердің электронды декларациясы
}

\author{
Нұркей А.А. ${ }^{1 *}$, Көшербаева А.Б. ${ }^{1}$, Куандықов Н.К. ${ }^{1}$ \\ ${ }^{1}$ Қазақ̆стан Республикасы Президенті жанындавы мемлекеттік басқ̧ару академиясы, Абай даңуд. \\ 33а, 010000, Нұр-Сұлтан, Қазақстан
}

\begin{abstract}
Түйін
Активтер туралы декларацияда теріс қылықтар мен заңсыз байытудың ашылуына көмектесетін, менеджерлердің жауапкершілікке тартылуын және олардың активтері сыбайлас жемқорлық жолымен алынбауын қамтамасыз ететін құнды ақпарат бар. Жалпы, табыс декларациясының электронды түрін қолдану сыбайлас жемқорлықпен күресуге оң әсер етеді. Дегенмен, көптеген оң қасиеттерге ие бола отырып, бұл түр көптеген кемшіліктер мен қиындықтарды қамтиды.Көптеген мемлекеттер мен халықаралық ұйымдар көлеңкелі экономиканың деңгейін төмендету үшін кірістер мен активтер туралы декларацияны енгізуде. Нәтижесінде табыстар мен активтерді декларациялау тәжірибесі ерте кезеңдерде енгізілген мемлекеттерде сыбайлас жемқорлық қылмыстарының деңгейі төмендегені анықталды. Дегенмен, бұл механизмді сыбайлас жемқорлыққа қарсы құрал ретінде қабылдау туралы пікірталастар әлі де бар. Бұл мақалада сыбайлас жемқорлықты жариялау мен онымен күресу саласындағы зерттеушілердің жұмыстары ғана емес, сонымен қатар тәжірибесі Қазақстанда да қолданыла алатын халықаралық зерттеулер қарастырылады. Бұл мақалада сыбайлас жемқорлыққа қарсы күрес әдісі ретінде электронды ақпарат құралдары арқылы кірістер мен активтер туралы декларацияны, оның ішінде әмбебап декларацияны қолдану тиімділігі қарастырылады. Талдау үшін SWOT талдауы таңдалды, оның көмегімен негізгі түйіндер бағаланды және ұсынымдар әзірленді, әсіресе қазақстандық сыбайлас жемқорлыққа қарсы саясаты бойынша. Бұл талдау нәтижесі электронды ресурстар арқылы әмбебап декларациялауды жүзеге асыру, әрине, тиімді қызмет екенін көрсетті, бірақ киберқауіпсіздік, бизнесті басқару процестерін оңтайландыру, техникалық қателіктер мен жүйенің бұзылуы сияқты шығындар мен қиындықтарды да ескеру қажет..
\end{abstract}

Түйін сөздер: сыбайлас жемқорлық, жалпыға бірдей декларация, цифрландыру, кірістер туралы декларация, сыбайлас жемқорлыққа қарсы күрес

Дәйексөз алу үшін: Нұркей А.А., Көшербаева А.Б., Қуандықов Н.К. (2021). Сыбайлас жемқорлықтың алдын алу әдісі ретінде активтердің электронды декларациясы. Экономика: стратегия және практика, 16(4), 208-217, https://doi.org/10.51176/1997-9967-2021-4 -208-217

* Хат-хабаршы авторы: Нұкрей А.А. - PhD кандидаты, Қазақстан Республикасы Президенті жанындағы мемлекеттік басқару академиясы, Абай даңғ. 33a, 010000, Нұр-Сұлтан, Қазақстан, 87172753497, a.nurkey@, gmail.com,

Мүдделер қақтығысы: авторлар мүдделер қақтығысының жоқтығын мәлімдейді.

Қаржыландыру. Зерттеу демеушілік қолдау көрсеткен жоқ (меншікті ресурстар).

Мақала редакцияға түсті: 07.10.2021

Жариялау туралы шешім қабылданды: 28.12.2021

Жарияланды: 30.12 .2021 


\title{
Декларирование активов в электронном виде как способ предотвращения коррупци
}

\author{
Нуркей А.А. ${ }^{1 *}$, Кошербаева А.Б. ${ }^{1}$, Куандыков Н.К. ${ }^{1}$ \\ 1-Академия государственного управления при Президенте Республики Казахстан, \\ пр. Абая 33а, 010000, Нур-Султан, Казахстан
}

\begin{abstract}
Аннотация
В декларации об активах содержится ценная информация, которая помогает раскрыть неправомерные дейсВ декларации об активах содержится ценная информация, которая помогает раскрыть неправомерные действия и незаконное обогащение, а также гарантирует, что руководители несут ответственность и приобретение их активов не происходит в результате коррупции. В целом использование электронного типа декларации доходов позитивно влияет на противодействие коррупции. Тем не менее, имея многочисленные положительные особенности данный вид также содержит ряд недостатков и трудностей. Многие государства и международные организации внедряют декларирование доходов и активов для снижения уровня теневой экономики. По итогу было выявлено, что в государствах, где практика декларирования доходов и активов была введена в раннем периоде уровень коррупционных преступлений снижен. Однако до сих пор существуют споры принятия данного механизма в качестве антикоррупционного инструмента. В данной статье рассматриваются не только работы исследователей в сфере декларирования и противодействия коррупции, но и международные исследования, опыт которых может быть использован также и в Казахстане. Данная статья рассматривает эффективность использования декларирование доходов и активов, в том числе и всеобщее декларирование, через электронные носители как способ противодействия коррупции. Для анализа выбран SWOT анализ, посредством него оценены основные ключевые моменты и выработаны рекомендации, в особенности для Казахстанской политики противодействия коррупции. Результат данного анализа показал, что внедрение всеобего декларирования через электронные ресурсы является безусловно эффективной деятельностью, однако также должны учитываться издержки и вызовы, такие как

кибербезопасность, упорядочивание бизнес-процессов управления, технические ошибки и сбои систем.
\end{abstract}

Ключевые слова: коррупция, всеобщая декларация, цифравизация, декларирование доходов, противодействие коррупции

Для цитирования: Нуркей А.А., Кошербаева А.Б., Куандыков Н.К. (2021). Декларирование активов в электронном виде как способ предотвращения коррупции. Экономика: стратегия и практика, 16(4), 208-217, https://doi.org/10.51176/1997-9967-2021-4-208-217 * Корреспондирующий автор: Нуркей А.А. - кандидат PhD, Академия государственного управления при
Президенте РК, пр. Абая 33a, 010000, Нур-Султан, Казахстан, 87172753497, a.nurkey@gmail.com

Конфликт интересов: авторы заявляют об отсутствии конфликта интересов.

Финансирование. Исследование не имело спонсорской поддержки (собственные ресурсы).

Статья поступила в редакцию: 07.10 .2021

Принято решение о публикации: 28.12 .2021

Опубликовано: 30.12 .2021 


\section{Введение}

Многие государства принимают и внедряют механизмы декларирования активов и раскрытие финансовой информации для публичных должностных лиц по рекомендациям Конвенции против коррупции ООН (далее КПК ООН). Данная инициатива набирает обороты и наблюдается тенденция принятия декларирования активов. Однако данный механизм не означает что это мероприятие может быть полезной в борьбе с коррупцией. Рассмотрим несколько примеров, когда, данная инициатива сыграла важную роль в борьбе с коррупцией. Так, например, в Филиппинах, Шри-Ланке и Таиланде по факту коррупции задержаны судьи и освобождены проректора высших учебных заведений. В Португалии также возбуждено дело против высшего руководства государственного банка на основании сданных деклараций [1]. Однако количество аналогичных кейсов ничтожно малы для того, чтобы утверждать, что декларация доходов является эффективным инструментом противодействия коррупции.

Многие экономические исследования коррупции рассматривали коррупцию в государственном секторе, изучая ее как способ обойти репрессивные правительственные постановления. Однако в последнее время большинство экономистов переосмыслили эту позицию и на данный момент подчеркивают неблагоприятные последствия коррупции для благосостояния. Некоторые аналитики критически относятся к правительству в целом - если коррупция появляется в государственном секторе, то имеет смысл ограничить их власть для удержания коррупции.

В данной статье будет рассмотрен вопрос эффективности декларирования доходов как инструмент противодействия коррупции. В качестве методологии будет использован SWOT анализ и международный опыт.

Одна из глобальных проблем современного мира определяет коррупцию, а потому борьбе с ней в любой стране необходимо уделять значительное внимание, а также разработать эффективные меры по противодействию этому негативному явлению.

Повсеместно все страны переводят документооборот в электронный вариант, развитие цифровизации является актуальным, в этой связи в данной статье будут рассмотрены процедуры декларирования доходов и активов посредством информационных технологий и электронных носителей.

Данный документ состоит из введения, где будут обозначены цели и основные вопросы исследования, основной части, в которой описывается применение декларации доходов, анализа посредством инструмента SWOT анализ. В конце статьи приведены рекомендации, заключение и список литературы соответственно.

\section{Литературный обзор}

Некоторые исследователи предпалагают приватизацию как эффективное средство борьбы с коррупцией [2]. Однако, хотя приватизация может иметь очевидные экономические преимущества, ее влияние на коррупцию неясно. Коррупцию можно просто переложить из государственного в частный сектор. Взятки, которые раньше брали государственные служащие, затем будут требовать сотрудники частных фирм. Приватизация также не дает гарантии того, что вновь созданные подразделения больше не служат политически мотивированным интересам. Точно так же сомнительно, способно ли уменьшенное в размерах правительство доить граждан: приватизированные фирмы могут в равной степени подвергаться государственному вмешательству и требованиям взяток. То, что раньше брали у государственных предприятий, теперь можно вымогать у частных фирм. Частные фирмы склонны платить больше неформальных платежей чем государственные служащие [3]. Многие развивающиеся страны испытали массовую коррупцию в самих программах приватизации. Это может быть еще одной причиной, почему сокращение государственного сектора не помогает снизить коррупцию, по крайней мере, в переходный период.

Бурдеску и др. утверждают, что не существует передовой практики борьбы c коррупцией и ее предотвращения через декларирование доходов. В своей работе, они также показывают, что эффективность декларирование зачастую зависит от некоторых индикаторов, таких как интенсивность проведения и масштаб декларирования [3].

Бигелоу П. в своих трудах заостряет внимание на законодательных факторах, которые четко должны регламентировать процесс декларации, а также усилить наказание через внедрения уголовно-процессуальной части. Усиление наказания влечет за собой снижение коррупции, то есть издержки за коррупцию окажутся выше выгод за нее [4].

Хотя исследования Гокчекус О. и Мукерджи Р. не выявило связи с закреплением декларации в законе и снижением коррупции. Данная научная работа показала, что в тех странах, где декларирование доходов установлено на законодательном уровне, 
среднее значение такого показателя как Индекс восприятия коррупции (ИВК) низкое, то есть данные государства уделяют большое внимание на восприятие коррупции [5]. Однако дела обстоят совершенно противоположно в тех странах, где конституционально не закреплен процесс декларирования.

В Таиланде только высокопоставленные чиновники и члены Парламента представляют декларацию о доходах в уполно- моченный орган по противодействию коррупции, тогда как доходы Премьер-министра и министров соответственно являются публично открытыми данными [6].

Дянков и др. считают, что куда более важно определить источник доходов нежели сам доход и его оценка. Данная информация может быть полезна не только следователям, но и для выявления конфликта интересов [7]. Анализ литературного обзора по факторам SWOT анализа представлена ниже ( таблица 1).

Таблица 1 - Анализ литературного обзора по факторам SWOT анализа [3-7]

Table 1 - Analysis of the literature review on the factors of SWOT analysis

\begin{tabular}{|c|c|c|c|c|}
\hline Авторы & $\begin{array}{c}\text { Годы } \\
\text { публикации }\end{array}$ & $\begin{array}{c}\text { Отношение } \\
\text { результатов к } \\
\text { противодействию } \\
\text { коррупции }\end{array}$ & Краткая характеристика & SWOT анализ \\
\hline Бурдеску Р. и др. & 2009 & негативное & $\begin{array}{l}\text { Зависимость от факторов } \\
\text { внедрения декларации }\end{array}$ & Threads \\
\hline Бигелоу П. & 1989 & позитивное & $\begin{array}{l}\text { Необходимость } \\
\text { ужесточения наказания }\end{array}$ & Strengths \\
\hline $\begin{array}{l}\text { Гокчекус О. } \\
\text { Мукерджи Р. }\end{array}$ & 2006 & негативное & Влияние на ИВК & Opportunities \\
\hline Дянков С. и др. & 2009 & позитивное & $\begin{array}{l}\text { Выявление } \quad \text { источника } \\
\text { информации }\end{array}$ & Strengths \\
\hline Ачалабун, П. & 2009 & негативное & $\begin{array}{l}\text { Сложность верификации } \\
\text { данных }\end{array}$ & weaknesses \\
\hline
\end{tabular}

Международные организации из года в год проводят анализ о состоянии коррупции во всем мире. Например, Трансперенси Интернейшнл в 2006 году провела сравнительный анализ по нормативных правовым актам о раскрытии данных об активах государств, продуктивность законов о декларировании имущества и активов государственных служащих для в предотвращении коррупционных правонарушений 42 странах [8]. В докладе приводился анализ через эконометрические инструменты по выявлению связи имеющихся нормативных правовых актов в сфере декларирования доходов и уровнем коррупции в этой стране. При анализе учитывались такие факторы как существование официальной документации о декларировании доходов, а также область распространения данного закона.
По итогу было выявлено, что в государствах, где практика декларирования доходов и активов была введена в раннем периоде уровень коррупционных преступлений снижен, в то время как, в странах, внедряющих эту практику недавно, культура нулевой толерантности к коррупции все еще не была сформирована. Также аналитики выяснили, что уровень коррупции не меняется в зависимости от вида декларации, то есть в странах, где все государственные служащие обязаны декларировать свои активы не отличаются от стран, где только высокопоставленные чиновники декларируют свои доходы.

Кроме того, выявлено что, уголовное наказание за сокрытие или иные правонарушающие деяния допускались в нормативных правовых актах о декларировании доходов в тех странах, где уровень восприятия коррупции был ниже. 
На уровень прозрачности также влияла проверка предоставляемой информации работников государственных учреждений.

На снижение коррупции также по мнению аналитиков влияет уровень прозрачности и открытости данных гражданам. В государствах, где любой человек мог проверить информацию об активах высокопоставленных лиц государства уровень коррупционных нарушений был значительно ниже по сравнению с другими странами, где не была предоставлена такая опция.

Корреляцию между снижением уровня преступности связанных с коррупционным правонарушением и двумя показателями (проверка предоставляемой информации и открытый доступ к информации касательно декларирования имуществ, доходов и активов высокопоставленных представителей государственного сектора) подтвердили при данном анализе.

Данные проведенных исследований Трансперенси Интернейшнл позволяют сделать предварительные выводы об эффективности внедрения такого инструмента как декларирование доходов при противодействии коррупции.

\section{Декларирование доходов в Казахстане}

Декларируют доходы не только государственных служащих, но и членов своих семей. Система декларирования запрашивает информацию об активах и доходах от членов семьи напрямую.

Также распространена практика получения декларации от бывших государственных служащих, чтобы посмотреть не получили ли они нелегальные активы после ухода с работы.

Законодательством Казахстана каждый гражданин будет обязан сдавать декларацию о доходах. Данную инициативу решено вводить в несколько этапов. Первый этап (с 1 января 2021 года) затронет государственных служащих и их супругов, а также лиц, приравненных к ним. Второй этап (с 1 января 2023 года) обяжет работников государственных предприятий, в том числе учителей, медицинских работников и других сдавать декларацию. На третьем этапе (с 1 января 2024 года) планируется вводить руководителей частных компаний и их супругов. Заключительный, четвертый этап (с 1 января 2025 года) охватит остальное население, не вошедшее в предыдущие три этапа [9].

Данная инициатива создана для отслеживания вероятных нелегальных передвижений денежных средств не только у государственных служащих, но и у всего работающего населения.
В целом практика декларирования доходов государственных служащих функционирует довольно много лет. С 2021 года начался первый этап обновления содержания декларации, были включены пункты касательно активов, дислоцированных за рубежом, в том числе имущественные доходы, денежные средства, кредиты и займы. Данная инициатива внедрена для определения активов в иностранных банках и финансовых организациях граждан Казахстана и имеет долгоиграющую перспективу в противодействии коррупции.

SWOT анализ использования механизма декларации доходов в качестве инструмента противодействия коррупции

В данной статье будет рассмотрен вопрос целесообразности использования электронного формата для всеобщего декларирования. Работа с большим количеством респондентов в данном случае должна учитывать все плюсы и минусы электронных носителей и других вызовов, связанных с цифравизацией.

Мы не можем отрицать необходимость оптимизировать бизнес-процессы, связанные с декларированием доходов. В Аргентине хранения деклараций активов на бумажном носителе являлось дорогостоящим с точки зрения использования полезной площади здания Министерства Юстиции. Данный вопрос являлся формальным, вместе с тем требовал дополнительных усилий и средств на содержание. Государством было решено в 2002 году 95 процентов декларации было переведено в электронный формат, что в большей степени оптимизировало пространство и ресурсы. В то же время государственные служащие столкнулись с другой немаловажной проблемой, из-за большего объема данных скорость обработки данных через компьютеры и технику резко снизилась [9].

Данный SWOT анализ проводился на основании научных работ и материалов международных организаций, указанных в списке литературы.

\section{Strengths}

- Использование больших данных при анализе. В случае использования электронных инструментов анализа больших данных (например, эконометрические инструменты SPSS, STATA, Statistica и т.д.) появляется возможность быстро и эффективно выявлять прецеденты и коррупционно-чувствительные направления. 
- Предотвращение незаконного обогащения. Режимы раскрытия информации о доходах и активах помогают предотвращать незаконное обогащение, через сверку зарегистрированного дохода с остальными регистрами (например, транспортные налоги, земельные и т.д.) и декларациями прошлых годов [10] Таким образом, раскрытие финансовой информации увеличивает издержки коррупции и может снизить склонность некоторых должностных лиц к незаконной финансовой практике. Однако сами системы не могут предотвратить коррупцию, данные системы помогают начать расследование через сбор систематических данных. Таким образом, раскрытие финансовой информации поддерживает более широкую стратегию борьбы с коррупцией, а также программы возвращения активов.

\section{Weaknesses}

- Использование наличных средств и транзакции в личных целях могут затруднить выявление нарушений.

- Сложность анализа больших данных, если вопрос касается всеобщего декларирования, выявляет уязвимость анализа, без соответствующих электронных инструментов анализа. Данный элемент является амбивалентным, так как при использовании правильных инструментов он автоматически становиться сильной стороной.

- Низкий показатель выявления коррупции через декларирование доходов и активов.

- Декларация во многих странах публичный документ, то есть

\section{Opportunities}

- Более широкое понимание антикоррупционной политики.

- Формирование этических поведенческих норм среди населения, в частности среди государственных служащих.

- Снижение фактов конфликта интересов. Во-первых, системы, нацеленные на конфликт интересов направлены на выявление потенциальных конфликтов интересов с самими государственными служащими, их руководством, контролирующими агентствами и, возможно при открытости данных, с гражданским обществом. Таким образом оповещение и открытость данных об активах служит примером сотрудникам о необходимости соблюдения честности и повышает осведомленность о потенциальных конфликтах интересов. Раскрытие информации также может прививать к формированию поведенческих норм, таких как порядочность и честность в общественных организациях [11].

\section{Threads}

- Доступ к информации на иностранных банковских счетах и кредитных картах является камнем преткновения для эффективной проверки, так как иностранные банковские счета прослеживать крайне тяжело. Для получения информации в иностранных банках и финансовых организациях необходимы двусторонние соглашения и иные международные правоустанавливающие процедуры и документы;

- Законы о банковской и налоговой тайнах также могут затруднить процесс обнародования доходов;

- Непроработанные взаимодействия и связи. Использование данных систем может быть неэффективной по причине недостаточности взаимодействия и связи с другими агентствами. Необходимо улучшить сотрудничество и системы обмена информацией через общие базы данных с другими организациями;

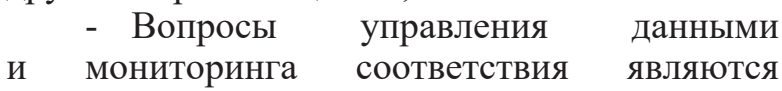
приоритетными для многих агентств по декларированию доходов

- Использование виртуальных активов и доходов. Например, посредством криптовалюты. Государства не могут отследить передвижение виртуальных денег. Данный вопрос является актуальным и по сей день [12].

\section{Рекомендации и обсуждение}

В целом использование электронного типа декларации доходов позитивно влияет на противодействие коррупции. Тем не менее, имея многочисленные положительные особенности данный вид также содержит ряд недостатков и трудностей.

С развитием информационных технологий в мире создаются все больше и больше инструментов, заменяющих денежные средства. Таким образом одним из будущих сложностей противодействия коррупции могут быть такие механизмы платежа как криптовалюта, биткойны и другие.

Система электронного декларирования также не может быть на сто процентов защищена в пространстве интернет. Поскольку любые формы государственного и негосударственного регулирования подвержены нападению через электронные системы. Несовершенство системы создает все больше пробелов для неэтичных граждан любого государства. Таким образом, встает вопрос кибербезопасности и защиты информационной системы. Это также потребует выделения 
дополнительных средств что повышает оперативные и капитальные затраты предприятий.

Однако, главным плюсом является создание возможности открытых данных. Многие страны стремятся к обеспечению прозрачности доходов и активов не только государственных служащих, но и всех граждан. Кроме того, ожидается что, данная деятельность поможет улучшить этическое поведение как услугодателей в лице работников государственного сектора, так и услугополучателей. Улучшение этической составляющей граждан также играет важную роль в антикоррупционной политике Казахстана.

Если сравнивать расходы и вероятную пользу данного инструмента мы можем предположить, что альтернативная прибыль долгоиграющая и не в скорой перспективе. То есть, пользу от этого мы сможем оценить через несколько лет или десятилетия, так как речь идет о смещении парадигмы среди всей возрастной группы населения страны. Мы также не можем не отрицать того факта, что потребуется дополнительные будущие расходы для правильного функционирования данного механизма.

\section{Заключение}

В декларации об активах содержится ценная информация, которая помогает раскрыть неправомерные действия и незаконное обогащение, а также гарантирует, что руководители несут ответственность и приобретение их активов не происходит в результате коррупции. Для успешного правоприменения требуется эффективный орган по мониторингу деклараций об активах c четкими полномочиями, полномочиями, возможностями, ресурсами и полномочиями для получения и обработки деклараций об активах государственных должностных лиц, a также для оценки их подлинности, полноты, неточностей и несоответствий.

В рамках работы декларации в электронном виде мы не имеем абсолютного положительного показателя. Так как данный механизм борьбы с коррупцией имеет как свои плюсы, так и свои минусы. Однако в долгосрочной перспективе польза от этого механизма противодействия коррупции ожидается выше чем предполагаемые издержки. Электронное декларирование доходов практикуется во многих странах. Также в некоторых странах данная мера распространяется не только на государственных служащих, но и для всего трудящегося населения. В рамках Казахстана данная инициатива внедряется постепенно, и мы можем сделать предварительно прогнозировать эффективность данного механизма.

Также стоит отметить, что механизм декларирования доходов является одним из ключевых инструментов борьбы с коррупцией и формирования культуры «Нулевой терпимости к коррупции» не только среди государственных служащих, но и среди всего населения страны.

\section{Список использованных источников}

1. Балисакан Р. (2018). Снижают ли обязательные декларации об активах коррупцию? И если да, то как?. Глобальный антикоррупционный блог. https://globalanticorruptionblog.com/2018/01/08/domandatory-asset-declarations-reduce-corruption-andif-so-how/

2. Всемирный банк. (2013). Раскрытие информации о доходах и активах: примеры из практики.

3. Ламбсдорф Дж.Г. (2006). Последствия и причины коррупции: что мы знаем по разным странам? Эдвард Эльгар Паблишинг (Edward Elgar Publishing) Международный справочник по экономике коррупции, 3-51.

4. Всемирный банк. (2013). Декларации об интересах, доходах и активах в системе раскрытия финансовой информации. Группа Всемирного банка по государственному сектору и управлению.

5. Бурдеску Р., Рид Дж.Дж., Гилман С. и Трапнелл С. (2009). Возврат украденных активов. Декларации о доходах и активах: инструменты и компромиссы. Вашингтон, округ Колумбия: Всемирный банк и УНП ООН. http://documents. worldbank.org/curated/en/126741468151478453/ pdf/550040W P0AD0in10Box349432B01PUBLIC1. pdf

6. Бигелоу П. (1989). От норм к правилам: регулирование внешних интересов государственных служащих. Труды Академии политических наук, 37(3), 141-157. http://www.jstor.org/stable/1173758

7. Гокчекус О. и Мукерджи Р. (2006). Законы о декларировании активов должностных лиц: предотвращают ли они коррупцию? Global Corruption Report http://works.bepress.com/omer_ gokcekus/36/

8. Чен М. (2008). Африканский опыт декларации активов. Трансперенси Интернейшнл. http:// www.anti-corruption.org/wp-content/uploads/2016/11/ Africas-experiences-with-asset-declarations-U4March-2008.pdf

9. Всеобщее декларирование доходов и имущества. (2021). Официальный сайт Правительства Республики Казахстан. https://www. gov.kz/memleket/entities/kgd-alm/press/article/ details/49826?lang=kk

10.Ачалабун П. (2009). Меры по замораживанию, конфискации и возвращению доходов от коррупции, включая предотвращение отмывания 
денег. UNAFEI, 117-127. http://www.unafei. or.jp/english/pdf/PDF_ThirdGGSeminar/Third GGSeminar_P1 17-127.pdf

11. Дяников С., Ла Порта Р., Лопес-де-Силанес Ф. и Шлейфер А. (2009). Раскрытие информации политиками. Серия рабочих документов NBER, 14703 http://www.nber.org/papers/w14703

12.Всемирный банк. Примеры из практики раскрытия информации о доходах и активах. (2013). Каталог публикаций Библиотеки Конгресса, Вашингтон, 16.

\section{References}

1. Balisakan, R. (2018). Do mandatory asset declarations reduce corruption? And if so, how?. Global Anti-Corruption Blog. https://globalanticorruptionblog. com/2018/01/08/do-mandatory-asset-declarationsreduce-corruption-and-if-so-how/

2. World Bank. (2013). Disclosure of income and assets: case studies.

3. Lambsdorff, J.G. (2006). Consequences and causes of corruption: what do we know from different countries? Edward Elgar Publishing International Handbook on the Economics of Corruption, 3-51.

4. World Bank. (2013). Declarations of interests, income and assets in the financial disclosure system. World Bank Group on Public Sector and Governance.

5. Burdescu, R., Reid, G. J., Gilman, S., \& Trapnell, S. (2009). Stolen asset Recovery. Income and asset declarations: tools and trade-offs. Washington DC: World Bank and UNODC. http://documents.worldbank. org/curated/en/126741468151478453/pdf/550040W P0AD0in10Box349432B01PUBLIC1.pdf
6. Bigelow, P. (1989). From norms to rules: regulation of the external interests of civil servants. Proceedings of the Academy of Political Sciences, 37(3), 141-157. http://www.jstor.org/stable/1173758

7. Gokcekus, O. \& Mukherjee, R. (2006). Laws on Declaration of Assets of Officials: Do They Prevent Corruption? Global Corruption Report http://works. bepress.com/omer gokcekus/36/

8. Chen, M. (2008). African experience of declaration of assets. Transparency International. http:// www.anti-corruption.org/wp-content/uploads/2016/11/ Africas-experiences-with-asset-declarations-U4March-2008.pdf

9. Universal declaration of income and property. (2021). Official website of the Government of the Republic of Kazakhstan. https://www.gov.kz/memleket/ entities/kgd-alm/press/article/details/49826?lang=kk

10. Achalaboon, P. (2009). Measures To Freeze, Confiscate And Recover Proceeds Of Corruption, Including Prevention Of Money-Laundering. Unafei, 117-127. http://www.unafei.or.jp/english/pdf/PDF ThirdGGSeminar/Third_GGSeminar_P1 17-127.pdf

11. Dyankov, S., La Porta, R., Lopez de Silanes, F., \& Shleifer, A. (2009). Disclosure by politicians. NBER Working Paper Series, 14703 http://www.nber. org/papers/w14703

13. World Bank. (2013). Examples from the practice of disclosure of information on income and assets. Catalog of Library of Congress Publications, Washington p. 16 


\section{Information about the authors}

* Aisulu A. Nurkey - Correspondent author, PhD candidate, Academy of Public Administration under the President of the Republic of Kazakhstan, e-mail: a.nurkey@gmail.com, ORCID ID: https://orcid.org/0000-0002-5999-7760

Aigul B. Kosherbayeva - Doctor of Economics, Academy of Public Administration under the President of the Republic of Kazakhstan, e-mail: a.kosherbayeva@apa.kz, ORCID ID: https://orcid.org/0000-0002-3096-0892

Nurzhan K. Kuandykov - PhD candidate, Academy of Public Administration under the President of the Republic of Kazakhstan, e-mail: knk91983@gmail.com, ORCID ID: https://orcid.org/0000-0003-0088-9025

\section{Авторлар туралы мәліметтер}

* Нұркей A.A. - PhD кандидаты, Қазақстан Республикасы Президенті жанындағы мемлекеттік басқару академиясы, e-mail: a.nurkey@gmail.com, ORCID ID: https://orcid.org/0000-0002-5999-7760

Көшербаева А.Б. - Экономика ғылымының докторы, Қазақстан Республикасы Президенті жанындағы мемлекеттік басқару академиясы, e-mail: a.kosherbayeva@apa.kz, ORCID ID: https://orcid.org/0000-0002-30960892

Куандықов Н.К. - PhD кандидаты, Қазақстан Республикасы Президенті жанындағы мемлекеттік басқару академиясы, e-mail: knk91983@gmail.com, ORCID ID: https://orcid.org/0000-0003-0088-9025

\section{Сведения об авторах}

* Нуркей А.A. - корреспондирующий автор, кандидат $\mathrm{PhD}$, Академия государственного управления при Президенте PK, e-mail: a.nurkey@gmail.com, ORCID ID: https://orcid.org/0000-0002-5999-7760

Кошербаева А.Б. - доктор экономических наук, Академия государственного управления при Президенте РК, e-mail: a.kosherbayeva@apa.kz, ORCID ID: https://orcid.org/0000-0002-3096-0892

Куандыков Н.К. - кандидат PhD, Академия государственного управления при Президенте РК, е-таil: knk91983@gmail.com, ORCID ID: https://orcid.org/0000-0003-0088-9025 